\title{
Echocardiographic abnormalities in ruptured chorda tendinae of rheumatic mitral valve
}

\author{
BL CHIA, MAURICE H CHOO \\ From the Division of Cardiology, Department of Medicine, National University of Singapore
}

The $M$ mode and two dimensional echocardiographic abnormalities of ruptured chorda tendinae of the mitral valve leaflets in non-rheumatic mitral valve disease have been well documented. ${ }^{2}$ Echocardiographic abnormalities in ruptured chorda tendinae occurring in chronic rheumatic mitral valve disease, however, have rarely been described..$^{4}$

\section{Case report}

A 55 year old white woman presented with a one year history of progressive dyspnoea. She had rheumatic fever during her teens and was known to have had a cardiac murmur for many years. Clinical examination revealed a loud pansystolic murmur that was loudest at the apex. The blood pressure was $120 / 85 \mathrm{~mm} \mathrm{Hg}$. The chest radiograph showed cardiomegaly and an enlarged left atrium. The electrocardiogram showed atrial fibrillation and evidence of left ventricular hypertrophy. Two dimensional echocardiographic examination using the parasternal long axis view showed a dilated left atrium and left ventricle. The aortic root and aortic valve leaflets were normal. Both the anterior and the posterior mitral valve leaflets were thickened. The anterior leaflet showed slight bowing towards the left ventricle in diastole but the posterior leaflet was immobile. An echo dense structure with considerable oscillation also was clearly seen in the region of the mid left ventricle (fig 1 ). This oscillating structure we believe to represent the ruptured chorda tendinae of the anterior mitral leaflet, which was later confirmed at operation. In systole the anterior mitral leaflet was seen to prolapse into the left atrium (fig 2). The tips of both the anterior and the posterior mitral leaflets, however, coapted normally in systole. When the parasternal short axis view was used both mitral leaflets were seen to be thickened. The mitral valve orifice measured $1.25 \mathrm{~cm}^{2}$ in end diastole (fig 3). An M mode echocardiogram obtained via a cursor line during two dimensional echocardiography also showed grossly thickened mitral valve leaflets. With the cursor line positioned across the ruptured chorda tendinae oscillating echoes were seen in the left ventricular cavity.

Cardiac catheterisation and angiography were then performed. The pulmonary artery pressure was $60 / 38 \mathrm{~mm} \mathrm{Hg}$

Address for reprint requests: Professor BL Chia, University Department of Medicine II, Singapore General Hospital, Singapore 0316

Accepted 12 April 1984 and the left ventricular end diastolic pressure was $18 \mathrm{~mm} \mathrm{Hg}$. Left ventricular angiography showed a dilated left ventricle with good contraction and severe grade IV mitral regurgitation. The aetiology of the mitral regurgita-

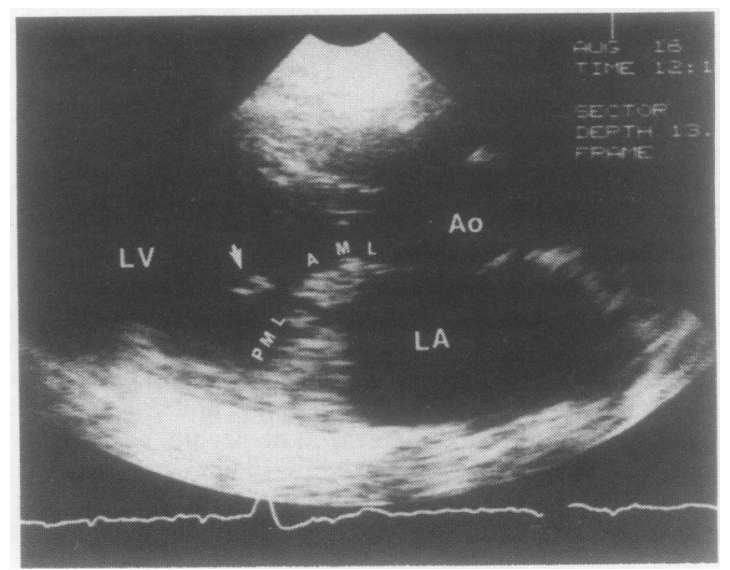

Fig 1 Parasternal long axis view (in diastole) showing grossly thickened anterior mitral leaflet (AML) and posterior mitral leafiet (PML). Arrow indicates echo dense structure with considerable oscillation. Ao-aortic root; $L A$-left atrium, $L V$-left ventricle.

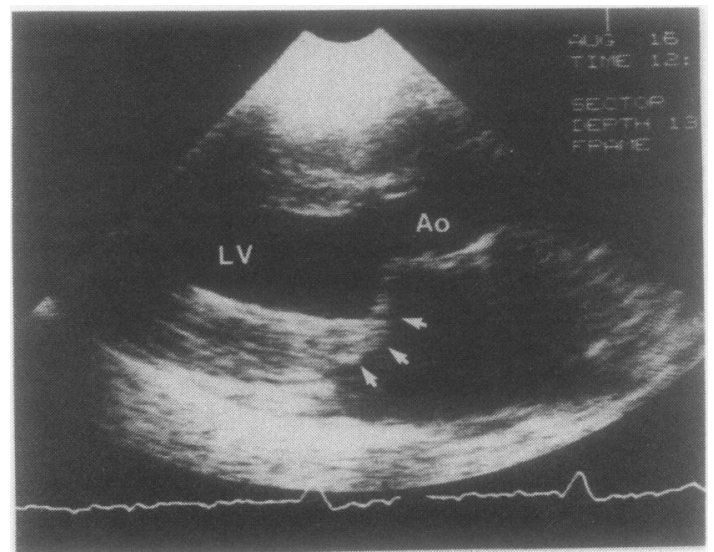

Fig 2 Parasternal long axis view (in systole) showing prolapse of the anterior mitral leaflet (arrows). LV-left ventricle; Ao-aorta. 


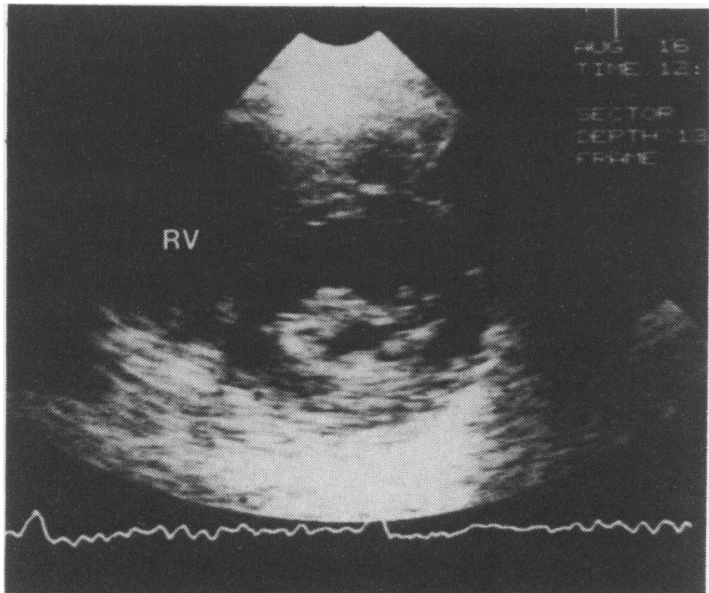

Fig 3 Parasternal short axis view in diastole showing thickened anterior and posterior mitral valve leaflets. $R V$-right ventricle.

tion could not be determined from the left ventriculogram.

At open heart surgery performed under cardiopulmonary bypass both mitral valve leaflets were found to be thickened and fibrotic. The posterior valve leaflet was grossly shrunken and rolled inwards. The chordae tendinae of both leaflets were also thickened, and a major chorda to the anterior mitral valve leaflet was found to be ruptured. The diseased mitral valve was excised and replaced with a Carpentier Edwards bioprosthetic valve. Histological examination of the excised valve showed considerable fibrosis, compatible with rheumatic valve disease. The postoperative recovery was unremarkable. Eight months after the operation the patient was reviewed and found to be well.

\section{Discussion}

The value of $M$ mode and two dimensional echocardiography for diagnosing rupture of chordae tendinae in nonrheumatic valve disease has been well established..$^{1-2}$ This case shows that two dimensional echocardiography may also be useful for diagnosing rupture of chordae tendinae of the mitral valve leaflets in rheumatic mitral valve disease. The thickened mitral valve leaflets and the ruptured chorda itself can all be clearly demonstrated, as was seen in this patient. The sensitivity and specificity of the method, however, in rheumatic mitral valve disease are at present unknown and must await further reports.

We would like to thank Dr Charles Toh for referring the patient for echocardiographic and haemodynamic studies and Dr Joseph Sheares and colleagues for operating on her.

\section{References}

' Humphries WC, Hammer WJ, McDonough MT, Lemole G, McCurdy R, Spann J. Echocardiographic equivalent of a flail mitral leaflet. Am J Cardiol 1977;40:802-7.

${ }^{2}$ Mintz GS, Kotler MN, Segal BL, Parry WR. Two-dimensional echocardiographic recognition of ruptured chordae tendinae. Circulation 1978;57:244-50.

${ }^{3}$ Ogawa S, Dupler DA, Paulette FJ, Chaudry K, Dreifus L. Flai mitral valve in rheumatic heart disease. Chest 1978; 74:88-90.

${ }^{4}$ Mourant AJ, Weaver J, Johnston K. Echocardiographic findings in rheumatic mitral valve disease with chordal rupture. $J$ Clin Ultrasound 1982;10:79-81. 